AperTO - Archivio Istituzionale Open Access dell'Università di Torino

\title{
Histamine and diabetic nephropathy: An up-to-date overview
}

\section{This is the author's manuscript}

Original Citation:

Availability:

This version is available http://hdl.handle.net/2318/1721864

since 2020-01-08T14:48:24Z

Published version:

DOI:10.1042/CS20180839

Terms of use:

Open Access

Anyone can freely access the full text of works made available as "Open Access". Works made available under a Creative Commons license can be used according to the terms and conditions of said license. Use of all other works requires consent of the right holder (author or publisher) if not exempted from copyright protection by the applicable law. 


\section{IIIS AperTO}

This is the author's final version of the contribution published as:

Pini A., Verta R., Grange C., Gurrieri M., Rosa A. C. Histamine and diabetic nephropathy: An up-to-date overview, Clinical Science, 133 (1), 2019, 4154, 10.1042/CS20180839

The publisher's version is available at: http://www.clinsci.org/

When citing, please refer to the published version.

\section{Link to this full text:}

https://portlandpress.com/clinsci/article-lookup/doi/10.1042/CS20180839 
Histamine and diabetic nephropathy: an up-to-date overview

Alessandro Pini* ${ }^{1}$, Roberta Verta ${ }^{* 2,3}$, Cristina Grange ${ }^{3}$, Maura Gurrieri ${ }^{2}$, Arianna Carolina Rosa $^{2}$

* Authors contributed equally to this work

${ }^{1}$ Department of Clinical and Experimental Medicine, University of Florence, Viale Pieraccini 6, 50139, Florence, Italy; ${ }^{2}$ Dipartimento di Scienza e Tecnologia del Farmaco, University of Turin, Via P. Giuria 9, 10125, Turin, Italy; ${ }^{3}$ Dipartimento di Scienze Mediche, University of Turin, C.So Dogliotti 14, 10126 Turin, Italy

Corresponding author: Arianna Carolina Rosa, PhD,

Dipartimento di Scienza e Tecnologia del Farmaco,

Università di Torino, Corso Raffaello 33, 10125, Turin, Italy

Phone: +390116707955

Fax: +390116707688

e-mail: ariannacarolina.rosa@unito.it 


\begin{abstract}
The classification of diabetic nephropathy (DN) as a vascular complication of diabetes makes the possible involvement of histamine, an endogenous amine that is well known for its vasoactive properties, an interesting topic for study. The aim of the present review is to provide an extensive overview of the possible involvement of histamine in the onset and progression of DN. The evidence collected on the role of histamine in kidney function together with its well-known pleyotropic action suggest that this amine may act simultaneously on glomerular hyper-filtration, tubular inflammation, fibrosis development and tubular hypertrophy.
\end{abstract}




\section{Abbreviations list}

AGEs = glycoxidation end-products; ALEs = advanced lipoxidation end-products; $\mathrm{BMM}=$ bone marrow derived macrophages; $\mathrm{CNDP} 1=$ carnosinase-1 gene; $\mathrm{DN}=$ diabetic nephropathy; $\mathrm{EDHF}=$ endothelium-derived hyperpolarizing factor; EDNO = endothelium-derived nitric oxide; GFR = glomerular filtration rate; $\mathrm{HDC}=$ histidine decarboxylase; $\mathrm{HNEpCs}=$ human nasal epithelial cells; HRs = histamine receptors; HUVECs = human umbilical vein endothelial cells; IL = interleukin; $\mathrm{MAPK}=$ mitogen activated protein kinase; $\mathrm{MC}=$ mast cells; NF- $\kappa \mathrm{B}=$ nuclear factor- $\kappa \mathrm{B} ; \mathrm{NHE} 3=$ $\mathrm{Na}^{+}-\mathrm{H}^{+}$exchange 3; $\mathrm{NO}=$ nitric oxide; PAS = periodic acid-Schiff; PBMCs $=$ peripheral blood mononuclear cells; PKC = protein kinase $\mathrm{C}$; RAAS $=$ renin-angiotensin-aldosterone; $\mathrm{SD}=$ slit diaphragm; $\mathrm{SGLT}=$ sodium glucose co-transporter; $\mathrm{SK}_{\mathrm{Ca}}=\mathrm{Ca}^{2+}$-activated $\mathrm{K}^{+}$channels; $\mathrm{TF}=$ tissue factor; TGF $=$ tubulo-glomerular feedback $;$ TGF- $\beta 1=$ transforming growth factor- $\beta 1$; TNF- $\alpha=$ tumour necrosis factor; ZO-1 = Zonula Occludens 1

\section{Perspectives section:}

- Histamine is a vasoactive amine involved in inflammatory response and fibrosis processes in the kidneys.

- DN can be considered a vicious self-potentiating circle between glomerular hyper-filtration, tubular inflammation, fibrosis development and tubular hypertrophy.

- Histamine targeting may be suitable as an adjuvant treatment for DN furnishing an integrated vasculoprotection, chronic inflammation reduction and fibrosis prevention approach. 
Diabetic nephropathy (DN) affects about one third of diabetes mellitus patients and is associated with a substantially elevated mortality rate (1), which is due to an increase in all-cause mortality and a concomitant decline in renal function. The main pharmacological strategies for its treatment currently involve the blockade of the renin-angiotensin-aldosterone (RAAS) system. However, these approaches are suboptimal and their efficacy greatly depends on the early initiation of therapy. The search for new therapeutic strategies is therefore highly warranted, but still a challenge that requires a better understanding of DN pathogenesis.

DN can be considered the result of the interactions between multiple metabolic and hemodynamic factors that activate common intracellular signalling pathways, such as protein kinase C (PKC), mitogen activated protein kinase (MAPK) and nuclear factor- $\kappa \mathrm{B}(\mathrm{NF}-\kappa \mathrm{B})$, which, in turn, trigger the production of cytokines and growth factors, leading to renal disease (2). The RAAS system, endothelin and urotensin II are vasoactive hormones that have been extensively studied. Other mediators may be involved, although their relation to DN is still speculative. In particular, histamine, in keeping with its well-known vascular and pro-inflammatory effects, is an interesting target for exploration. Indeed, DN is considered a microvascular compliance of diabetes which establishes a vicious circle between glomerular hyper-filtration, tubular inflammation, hypertrophy and interstitial fibrosis development, with synergistic effects. The identification of mediators that can simultaneously affect these multiple events would translate into new pharmacological targets. Histamine was initially related to the vascular genesis of glomerular hyper-filtration. However, a more complex role for histamine can be hypothesised since the tubular hypothesis of DN pathogenesis was postulated. This review aims to elucidate histamine's contribution to the vicious circle of DN. 


\section{Histamine source in diabetic kidneys}

Markle R.A. et al. (1986) were the first to demonstrate that diabetic rats show an increase in whole kidney histamine content, of up to $45 \%$. Notably, they also used a pharmacological approach to provide the first evidence that this increase was due to the neo-synthesis of histamine from its precursor L-histidine by the histidine decarboxylase (HDC) enzyme. Indeed, the administration of the selective HDC inhibitor $\alpha$-hydrazinohistidine $(25 \mathrm{mg} / \mathrm{kg} /$ day ip for 2 weeks), inhibited this increase almost to control levels (3). These data are consistent with the increased systemic level of histamine reported in diabetic patients with peripheral vascular disease (4), suggesting that histamine may play a functional role in the development of diabetes and its microvascular complications. This hypothesis has been supported by the more recent observation that the deletion of the histidine decarboxylase (HDC) enzyme, which synthesizes histamine from its precursor L-histidine and can therefore be considered a marker for histamine biosynthesis (5), prevents the development of autoimmune diabetes in NOD mice (6). However, these data draw attention to the question of whether the source of histamine in diabetic kidneys is systemic circulation or a local inducible histamine pool. The first hypothesis has actually been discarded after the observation of the presence of the HDC enzyme in the kidney specimens of both humans and mice. Indeed, the histamine concentration in the glomeruli was found to be much higher than the circulating concentration $\left(10^{-6} \mathrm{M} v s 10^{-8} \mathrm{M}\right.$, respectively) (7). In particular, it was demonstrated, using an enzymatic assay on tissue homogenates, that diabetic rats show significantly higher HDC renal activity $(+79 \%)$ and no decreases in the activity of histaminase, which is one of the enzymes that catalyses histamine decomposition, in tissues (8). Consequently, an increase of up to $81 \%$ in histamine content in the kidneys of diabetic rats, as compared to controls, has also been demonstrated (9). Attempts to identify mast cells (MC) in the kidneys were pursued for a long time as mast cells are the main source of histamine in tissue. The MC number in the kidneys is typically very low (10), in non-diabetic conditions, unlike in other anatomical districts where $\mathrm{MC}$ can be constitutively found. However, their presence increases in a variety of human diseases (10), including DN. Increased numbers of MC that express type VIII 
collagen (11), as well as MC chymase and tryptase (12), have been observed in the renal biopsies of DN patients. Notably, several hyperglycaemia-related metabolic by-products (such as ROS and oxidized lipoproteins) trigger MC degranulation (13), which has been found to parallel the development of DN through the stages of the disease (12). The role of MC in DN involves the activation of the local RAAS systems, via the release, by MC, of chymase, a chymotrypsin-like serine protease potent inducer of angiotensin II (14). However, histamine that is released from MC may also contribute to RAAS system activation (15). In 1982, Schwertschlag U. and Hackenthal E. demonstrated that MC-derived histamine was able to stimulate the release of renin from rat kidneys by $\mathrm{H}_{2} \mathrm{R}$ activation (16).

Despite HDC in MC is usually the major source of histamine and renal MCs are increased in DN together with the histamine levels, a non-MC HDC is considered to be the prevalent source of histamine. Indeed, three observations have to be considered: (i) renal histamine content in nondiabetic conditions, in which MC number is very low, is already higher than plasmatic content $\left(10^{-6}\right.$ $\mathrm{M} v s 10^{-8} \mathrm{M}$, respectively) (7); (ii) compelling evidence from both enzymatic assays (on homogenates of glomeruli and tubules from the medulla and cortex) and immunohistochemical analyses (on isolated cells and kidney specimens) revealed that HDC was localised mainly in the cortex, both in the glomerulus $(7,17)$ and tubules $(18,19)$; (iii) HDC expression on renal residential cells was found to be significantly up regulated in diabetic mice (19). Collectively, these data clearly demonstrate the existence of a local intra-renal inducible histamine pool. Interestingly, it has been shown that carnosine, which is a dietary essential amino acid whose plasmatic levels are low in chronic kidney disease patients (20), is an adjunctive reservoir for L-histidine. Carnosine, which is a dipeptide formed of $\beta$-alanine and L-histidine, has been found in several histamine-rich anatomical districts, including the kidneys, in an inverse correlation with histamine levels (21). Interestingly, polymorphism in the the gene encoding for carnosinase-1 (CNDP1), which is a circulating enzyme that degrades the dipeptide carnosine into $\beta$-alanine and L-histidine, has been associated with the risk of nephropathy in type 2 diabetic patients. However, carnosine treatment has been found to restrain 
glomerular apoptosis, to prevent podocyte loss and to reduce the expression of Bcl-2-associated X protein and cytochrome c (22), by inhibiting advanced glycoxidation end-product (AGEs) and advanced lipoxidation end-product (ALEs) formation (23), via an histamine independent pathway.

The detrimental effect of histamine in diabetic kidneys can be mediated by all four of its receptors (HRs). Indeed, a complementary immunohistochemical and pharmacological approach has demonstrated that they are all expressed in the kidneys: $\mathrm{H}_{1} \mathrm{R}$ had the widest distribution as it was present in the glomeruli (podocyte and mesangial cells) and both the proximal and distal tubules; $\mathrm{H}_{2} \mathrm{R}$ shared the glomeruli (mesangial cells) and distal tubule localization with $\mathrm{H}_{1} \mathrm{R} ; \mathrm{H}_{3} \mathrm{R}$ seems to be restricted to the apical side of the principal cells of the collecting duct; $\mathrm{H}_{4} \mathrm{R}$ was found at the proximal tubules and at the loop of Henlé $(7,17,24-27)$. Notably, the up-regulation of the histaminergic tone in the diabetic kidney is related to the over expression of at least two of the four histamine receptors (HRs), which is in accordance with the increased renal histamine levels; in particular, $\mathrm{H}_{3} \mathrm{R}(26)$ at the collecting duct, and $\mathrm{H}_{4} \mathrm{R}$ mainly at the proximal tubules and at the loop of Henlé $(17,25)$. The potential contribution of HR activation to the DN vicious circle will be explored below.

\section{Histamine and glomerular hyper-filtration}

Glomerular hyper-filtration stems from mechanical damage to the glomerulus that involves podocyte detachment and loss, extracellular matrix deposition and endothelial dysfunction. Histamine is thought to participate in at least two of these detrimental events: podocyte detachment and endothelial dysfunction. It is well accepted that glomerular hyper-filtration reflects generalised microvascular and macrovascular functional changes (28-30). Its well-known vasoactive properties (31), led scientists to think that the nascent or inducible histamine pool observed in experimental models of diabetes triggered micro-vessel alterations and large vessel hyper-permeability, thus contributing to both the diabetic microangiopathy and macroangiopathy (32), that are at the base of glomerular hyper-filtration. In the aortic endothelial and subjacent smooth muscle cells of diabetic rats, HDC activity increased by $250 \%$ and over $300 \%$, respectively, over the 4 -week period after diabetes induction. Parallel histaminase activity was reduced by $50 \%$ in the aortic endothelial cells and by 
$30 \%$ in the subjacent smooth muscle cells and the intracellular histamine content increased to $138 \%$ and $150 \%$, respectively (33). The neo-synthesis of histamine at the aortic level was confirmed by the inhibitory effect of $\alpha-\mathrm{HH}$, which was also able to reduce the aortic albumin flux in diabetic rats by $83 \%$ (34). It can therefore be stated that histamine is clearly a mediator of aortic macromolecule uptake in diabetes. Nevertheless, histamine levels in coronary circulation were found to increase during myocardial ischemia, irrespective of the incidence of risk factors, diabetes included (35).

The increased histaminergic tone on the vascular level can trigger hyper-permeability in various microcirculatory beds. For instance, diabetic rats shown an increased blood-brain barrier permeability within 2 to 4 weeks after the onset of hyperglycaemia, and this effect was mediated by $\mathrm{H}_{1} \mathrm{R}(36-39)$. Youisf M.H. et al. (40) have demonstrated, in an ex-vivo perfused kidney model, that exogenous histamine-induced vasodilation in diabetic-rat-derived kidneys is mediated by both endotheliumderived nitric oxide (EDNO) and the endothelium-derived hyperpolarizing factor (EDHF), which open the $\mathrm{Ca}^{2+}$-activated $\mathrm{K}^{+}$channels $\left(\mathrm{SK}_{\mathrm{Ca}}\right)$. $\mathrm{SK}_{\mathrm{Ca}}$ have been found to have no impact on afferent arteriolar tone in normal kidneys (41). However, $\mathrm{SK}_{\mathrm{Ca}}$-mediated relaxation is reduced in the resistance arteries of diabetic rats (42-44). It is worth noting that the well-known anti-diabetic drug metformin has been found to restore $\mathrm{SK}_{\mathrm{Ca}}$-mediated vasodilatation, which had been impaired by $\mathrm{AGEs}$ in rat mesenteric arteries (45).

Histamine is known to act biphasically on vascular permeability: within seconds to minutes, it evokes a rapid transient increase in permeability that is caused by endothelial gaps (46-51), while within hours it causes prolonged vascular leakage by acting on the expression of the zonula occludens (ZO)1 protein (52). These events have been explored particularly at the ocular level in order to test the hypothesis that histamine may act as a mediator of diabetic retinopathy. Gardner T.W. (1995) demonstrated that histamine contributes to the retinal blood barrier permeability breakdown in diabetic retinopathy $(53) . \mathrm{H}_{1} \mathrm{R}$ antagonism could therefore be a therapeutic strategy for diabetic retinopathy and the hypothesis of the use of a similar strategy for DN has also appeared (54). However, the Astemizole Retinopathy Trial, which aimed to evaluate the efficacy of the $\mathrm{H}_{1} \mathrm{R}$ 
antagonist in diabetic macular oedema, revealed no clinical effect (55), leading to the strategy being abandoned for the treatment of DN.

In the kidney, histamine can affect the integrity of permeability barriers. Indeed, histamine has been reported to affect ZO-1 and P-cadherin expression in human immortalised podocytes (17). Both of these junctional proteins play pivotal roles in maintaining the cytoarchitecture of the slit diaphragm (SD), and disturbing them may contribute to podocyte detachment and loss. Notably, only chlorpheniramine, a selective anti- $\mathrm{H}_{1} \mathrm{R}$, was effective in preserving SD integrity, including a potential positive effect on the prevention of podocyte loss and consequently on glomerular-filtration barrier integrity, while ranitidine (selective $\mathrm{H}_{2} \mathrm{R}$ antagonist) and JNJ7777120 (the $\mathrm{H}_{4} \mathrm{R}$ antagonist prototype) provided no effect (17). Histamine may therefore exert direct effects on glomerular hyper-filtration, through $\mathrm{H}_{1} \mathrm{R}$, in addition to its well-known vascular activities. Notably, levocetirizine $(0.5 \mathrm{mg} / \mathrm{kg} / \mathrm{day}$ orally for 8 weeks) increased creatinine and urea clearance in a model of streptozotocin-induced diabetes in rats, and almost restored the glomerular filtration rate (GFR), while simultaneously reducing proteinuria and polyuria (56). Although a quantitative morphological analysis of the filtration barrier was not performed, the functional data, together with the classical histological by periodic acid-Schiff (PAS)- and Masson's trichrome-staining, support the existence of a beneficial effect on glomerular filtration barrier integrity. These data are in keeping with the observation by Ichikawa and Brenner (1979) of a decrease in the ultrafiltration coefficient following $\mathrm{H}_{1} \mathrm{R}$ activation. Moreover, a drop in the GFR evoked by aortic clamping was observed after the infrarenal infusion of different $\mathrm{H}_{1} \mathrm{R}$ antagonists/inverse agonists (Banks 1984). However, in a model of anti-glomerular basement membrane induced glomerulonephritis both the $\mathrm{H}_{1} \mathrm{R}$ antagonist diphenhydramine and the $\mathrm{H}_{2} \mathrm{R}$ antagonist cimetidine prevented the GFR decrease (Wilson et al., 1981). GFR derives from the sum of the hydrostatic pressure in the glomerular capillaries, the hydrostatic pressure in the Bowman's capsule or the proximal tubule, the colloid osmotic pressure of the glomerular capillaries and the colloid osmotic pressure of Bowman's capsule (Persson et al., 2010). The early phase of DN is characterized by an increased GFR and renal plasma flow (Barnes et al., 1989). Histamine induced 
vasodilation (Yousif) could account at least in part to the early GRF increase observed in DN. Later on, with the disease progression the GFR declines in parallel with a further rise in albuminuria, consequently to an increase in the colloid osmotic pressure of the glomerular capillaries and hyperfiltration (Palatini et al., 2012), possibly through the disturbance of the tubulo-glomerular feedback (TGF) (Persson et al., 2010). Therefore, it is possible that the histamine receptors expressed on the tubules, proximal tubule in particular, could account for GFR decline in the later phase. Notably, apart the $\mathrm{H}_{1} \mathrm{R}$, also $\mathrm{H}_{4} \mathrm{R}$ could be involved in GFR modulation, as its blockade by JNJ39758979 restored to control the drop in Creatinine Clearance, an approximate measure of the GFR, observed in after 15 weeks of diabetes in a mouse model of diabetes (PINI, 2018).

\section{Histamine and tubular inflammation}

Tubular inflammation is a hallmark of progressive renal disease (Tang and Lai, 2012). DN inflammation is sterile and chronic, triggered by intrinsic kidney cell injury (Zheng and Zheng, 2016), which can produce a number of chemokines promoting a proinflammatory microenvironment that amplifies renal injury (Lim and Tesch 2012). These events promote the kidney infiltration of monocytes and lymphocytes which further amplifies the inflammatory response, promotes cell injury and the development of fibrosis (Lim and Tesch 2012).

The inflammatory properties of histamine were among the first properties described for the amine (57). Indeed, according to the triple response described by Lewis in 1924, the vascular changes that occur in acute inflammation are accompanied by the recruitment of neutrophils and mononuclears, which cross the endothelial junctions and penetrate the vessel wall. Leukocytes are thereafter recruited through chemotaxis. Two of the four HRs are implicated in these events: $\mathrm{H}_{1} \mathrm{R}$ promotes cellular migration (58), while $\mathrm{H}_{4} \mathrm{R}$ activation mediates eosinophil adhesion to the endothelium, and chemotaxis (59), up-regulating the cell-surface proteins CD11b/CD18 (Mac-1) and CD54 (ICAM-1) on human eosinophils (60). Following $\mathrm{H}_{4} \mathrm{R}$ activation, the rearrangement of the actin cytoskeleton of eosinophils facilitates cell migration into the inflammation sites (61). Notably, Dai D.F. et al. (62) 
have demonstrated that interstitial eosinophil aggregation is more common in the renal biopsies of DN patients than in other types of glomerulopathy, such as IgA nephropathy, membranous nephropathy and membranoproliferative glomerulonephritis. Moreover, the severity of interstitial fibrosis and tubular atrophy was the only predictor factor for interstitial eosinophil aggregation in DN. It is reasonable to conclude that eosinophil aggregation is a consequence of inflammatory response and that it perpetuates tubulointerstitial injury. Notably, the preventive chronic administration of the $\mathrm{H}_{4} \mathrm{R}$ antagonist JNJ39758979 $\left(K_{\mathrm{i}}=12.5 \pm 2.6 \mathrm{nM}\right)$ led to a significant reduction in the number of leukocytes, compared to untreated diabetic animals, 15 weeks after diabetes onset in a model of streptozotocin-induced DN in DBA2/J mice (19).

The chemotactic effects of histamine not only involve eosinophils, but also neutrophils: they evoke lysosomal enzyme release (63), and thus enhance the inflammatory response to direct tissue damage. Histamine is also involved in T cell proliferation and lymphokine release, the induction of cytotoxic T cells and the promotion of their cytolytic activity, as well as B cell differentiation into effector cells (64). All these infiltrating cells contribute, together with macrophages, dendritic cells, and renal tubular cells to inflammation in DN (Zheng and Zheng, 2016).

Beyond inflammatory cell recruitment, histamine is also known to exert other inflammatory properties in several cellular systems. For instance, histamine activates the NF- $\kappa \mathrm{B}$ pathway by

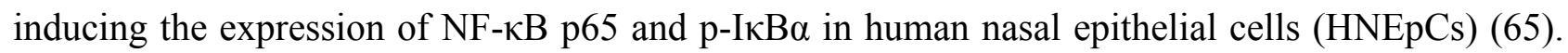
The $\mathrm{H}_{1} \mathrm{R}$ antagonist cetirizine has been demonstrated to not only inhibit the recruitment and activation of inflammatory cells, but to also suppress the production of reactive oxygen radicals and lipid mediators (66-69). It is therefore possible to speculate that similar effects are evoked by histamine in renal cells.

More interestingly, histamine, acting both as a paracrine and autocrine stimulus, has been observed to increase the mRNA levels of interleukin (IL)-6 (65), a cytokine involved in several renal diseases including DN $(70,71)$. In particular, IL-6 overexpression in diabetic kidneys has been correlated with 
kidney hypertrophy, albumin excretion, mesangial expansion and glomerular basement membrane thickening (Lim and Tesch, 2012).

Another factor that has been extensively linked to DN is IL-18 (72), which serum and urinary levels have been previously correlated with albuminuria $[50,91]$. The major source of this proinflammatory cytokine are the tubular epithelial cells, but it is produces by infiltrating monocyte-macrophages and T cells $[89,90]$. The induction of IL-18 secretion from peripheral blood mononuclear cells (PBMCs) (73) may be an additional contribution to the inflammatory milieu of DN by histamine. However, a more recent study has demonstrated the existence of functional antagonism between IL-18 and histamine, which occurs via $\mathrm{H}_{2} \mathrm{R}$ stimulation, in monocyte ICAM-1 expression (74).

On the other hand, the effect of histamine on tumour necrosis factor (TNF)- $\alpha$, another relevant proinflammatory cytokine that is associated/involved with DN and interstitial tubular nephritis (75), is contradictory. TNF- $\alpha$ has been implicated haemodynamic changes affecting the GFR [45-48] and the endothelial permeability [49] and its urinary excretion has been correlated with DN progression [ [22]. TNF- $\alpha$ is produced not only by monocytes, macrophages, and T cells, but also by all the resident renal cells (Lim and Tesch, 2012). Moreover, TNF- $\alpha$ is stored and released by MC and can be released (76) together with histamine, which in turn can stimulate the release of TNF$\alpha$ in an autocrine manner (77). However, histamine has been reported to antagonise TNF- $\alpha$ by shedding its receptor, TNFR1, via $\mathrm{H}_{1} \mathrm{R}$ activation in human umbilical vein endothelial cells (HUVECs) (78) and to suppress TNF- $\alpha$ synthesis via $\mathrm{H}_{2} \mathrm{R}$ in PBMC and monocytes (79).

Finally, histamine is also able to activate the Tissue Factor (TF) pathway. It has been reported that endothelial TF expression and activity is induced by histamine (80), via $\mathrm{H}_{1} \mathrm{R}$ activation (81). TF expression is induced in vascular inflammation and involved in DN development (72), with its increasing associated with DN severity (WANG et al., 2010). 


\section{Histamine and tubular fibrosis}

The inflammatory properties of histamine and its role in promoting and sustaining inflammatory cell infiltration are linked to fibrosis development, which suggests that histamine may be a target for the management of kidney fibrosis. Glomerular and tubulointerstitial infiltration by inflammatory cells, including neutrophils, macrophages and lymphocytes, which release pro-fibrotic cytokines (82), occurs from the early stage of DN. Such cellular infiltrates have been reported in both animal experimental models and human renal biopsies (83). Of the various inflammatory cells involved, a prominent role can be attributed to macrophages, whose accumulation has been related to the severity of DN (84).

The differentiation of monocytes into macrophages has been associated with an imbalance in the native $\mathrm{HRs}$ on these cells. $\mathrm{H}_{1} \mathrm{R}$ is up-regulated during differentiation, thus increasing the histaminergic response, while $\mathrm{H}_{2} \mathrm{R}$ is down-regulated (85). The role of histamine in macrophage activation is further confirmed by in vitro data. $\mathrm{H}_{4} \mathrm{R}$ induces chemotaxis and phagocytosis in both human (RAW 264.7 cell line) and murine (bone marrow derived macrophages - BMM) monocytes (86). Finally, macrophages and lymphocytes have also been found to be an alternative source of histamine, with a content of ca. $0.05 \mathrm{pg}$ histamine/cell, in a histamine-specific radioimmunoassay. Both the ionophore A23187 and the complement component 5a caused histamine release, of up to $50 \%$ and $40 \%$, respectively, from monocytes (87).

Once again histamine is seen to induce and perpetuate the pathological events that underlie renal failure in DN, exerting both autocrine and paracrine effects on a range of inflammatory cells.

Macrophages are also a major source of transforming growth factor- $\beta 1$ (TGF- $\beta 1$ ), which is the master regulator of fibrosis and a potent chemoattractant for macrophages/monocytes. In DN, TGF- $\beta 1$ can be considered one of the principal mediators of parenchymal/stromal alterations, which finally lead to tissue architecture disruption (88). TGF- $\beta 1$ up-regulation causes the imbalance in extracellular matrix turn-over, promoting the excessive deposition of collagen fibres and inhibiting their 
degradation at the same time. TGF- $\beta 1$ also causes the trans-differentiation of parenchymal into stromal cells. For example, it brings about the transformation of tubule epithelial cells into myofibroblasts $(89,90)$. This process is responsible for interstitial renal fibrosis. TGF- $\beta 1$ overexpression, together with the consequent extracellular matrix accumulation and parenchymal cell trans-differentiation, is closely associated with renal failure (91). TGF- $\beta 1$ is therefore an attractive target when attempting to counteract fibrotic processes. The only current strategy that directly targets TGF- $\beta 1$ is based on the use of monoclonal antibodies, such as fresolimumab, for the treatment of pulmonary fibrosis (92). It has been tested in a phase 1 study for primary focal segmental glomerulosclerosis (93). However, recent data suggest that antihistamine anti- $\mathrm{H}_{4} \mathrm{R}$ compounds can be used to regulate TGF- $\beta 1$ release and effects. Indeed, in vivo studies carried out on a model of bleomycin-induced lung fibrosis clearly demonstrate that $\mathrm{H}_{4} \mathrm{R}$ antagonism counteracts fibrosis establishment by acting on TGF- $\beta$ production $(94,95)$. TGF- $\beta$, in turn, modulates the fibrotic process by impacting upon downstream signalling. Notably, the down-regulation of TGF- $\beta$ by JNJ7777120 (the $\mathrm{H}_{4} \mathrm{R}$ antagonist prototype) has been sustained by a reduction in Smad 3 phosphorylation and, consequently, Smad3/Smad4 complex formation (94). The Smad family is one of the most-commonly studied pathways and is closely involved with TGF- $\beta 1$. Focusing on the renal fibrotic process, the presence of Smad 3 and Smad 4 has been evaluated as being pathogenic while that of Smad 2 and Smad 7 has been related to renoprotective effects (96-99). The decreased level of Smad 7 expression causes persistent inflammation and, as result, leads to renal fibrosis via TGF- $\beta$ and Smad 3 . It is therefore plausible that the anti-fibrotic effect exerted by JNJ39758979 in a model of murine DN (19), is related, at least partially, to the modulation of TGF- $\beta /$ Smad signalling in the kidneys.

Nevertheless, $\mathrm{H}_{1} \mathrm{R}$ can also modulate the fibrotic response. Indeed, levocetirizine-treated diabetic rats have shown a reduction in renal TGF- $\beta 1$ (56). Whether this is a direct consequence of $\mathrm{H}_{1} \mathrm{R}$ antagonism, or rather an indirect event is still to be established. However, the anti-inflammatory effect, evaluated in terms of the restoration of TNF- $\alpha$ levels and nitric oxide (NO) bioavailability (56), may be a possible mechanistic interpretation of the anti-fibrotic result. Moreover, the presence 
of the $\mathrm{H}_{1} \mathrm{R}$ on kidney fibroblasts, whose activation promotes proliferation, TGF- $\beta$ synthesis and collagen production (Silver - 2013), further support the involvement of this receptor in fibrosis development.

Actually, no other study apart the one from Pini et al. (2018) and Anbar et al. (2016) evaluated the effect of histamine blockade on renal fibrosis during DN, therefore just speculation are possible so far. However, the measurements of TGF- $\beta 1$ renal level in diabetic rats treated with levocetirizine and the evaluation by Picrosirius red staining of collagen fibre deposition after JNJ39758979 (Anbar) treatment of diabetic mice (Pini) support the hypothesis that at least $\mathrm{H}_{1} \mathrm{R}$ and $\mathrm{H}_{4} \mathrm{R}$ are both involved, directly or indirectly (through the reduction of pro-inflammatory infiltrating cells), in renal fibrosis development.

\section{Histamine and tubular reabsorption}

Recently, proximal tubule as initiator, driver or contributor in the pathogenesis of DN become an intriguing hypothesis. Impaired tubular uptake and increased glomerular leakage are both potentially responsible for microalbuminuria early stage of DN (Zeni et al., 2017). Indeed, the existence of the TGF can explain a reduction in GFR during inhibition of proxiaml tubular reabsorption: the increased electrolyte load to the macula densa due to a reduction in reabsorption led to afferent arteriolar vasoconstriction and consequqntly to a GFR correction (Persson and Wright, 1982). Sodium and chloride appear to be the preferential elctrolyte regulating the TGF. This tubulo-centric hypothesis could be considered the basis for the development of the newest antidiabetic class, the sodium glucose co-transporter (SGLT)-2 inhibitors. Interestingly, their nephro-protective effects can be due to a functional link between SGLT2 and the $\mathrm{Na}^{+}-\mathrm{H}^{+}$exchange 3 (NHE)3, an important determinant of $\mathrm{Na}+$ tubular reabsorption, according to which when SGLT2 is inhibited also NHE3 is inhibited (Zeni et al., 2017).

Tubular reabsoprtion impairment could also contribute to albuminuria onset in DN (Dickson et al., 2014). Despite the canonical idea of an increase in creatinine and urinary albumin excretion due to 
glomerular hypertension and hyperfiltration in the early phase of DN (Brenner et al., 1996), more recent evidence are in favour of an unchanged glomerular albumin filtration, but a decrease in tubular albumin reabsorption (Tojo et al., 2001; Russo et al., 2009). Major contributor to albumin dynamics associated with the hyperfiltration status of DN is the megalin/cubilin complex (Amsellem et al., 2010). Interestingly, in two models of insulin-deficient diabetes in drug-inducible megalin knockout mice, both albumin filtration and reabsorption were increased (Mori et al., 2017).

Overall these evidence hilihgts the importance of tubular reabsorptive processes in DN onset and progression.

The role of histamine in tubular reabsorption has been less investigated than the other fields. Therefore, only speculation can be made, and most of them are based on a parallelism with other epithelial tissues. The only reabsorption mechanisms that have seen some partial investigation are the megalin and NHE3 pathways in the proximal tubule. Hyperglycaemia is known to induce a reduction in megalin expression and a parallel increase in NHE3 expression and activity (100). JNJ39758979 treatment preserved the expression and apical membrane localisation of megalin as well as the expression level of NHE3 in a mouse model of DN. These events were paralleled by a restoration of the albumin-to-creatinine ratio and creatinine clearance and by preserved glomerular integrity (19). In accordance with the tubular hypothesis of DN (101), it is therefore possible to speculate that JNJ39758979's beneficial effect on renal function is a consequence of its beneficial effect on the tubular reabsorption machinery. However, the question of whether this is a direct $\mathrm{H}_{4} \mathrm{R}$-blockade effect is still far from being answered. Indeed, we can only speculate whether histamine has a direct detrimental effect on the megalin and NHE3 pathways in terms of parallelism between the angiotensin AT-1 receptor and H4R, which are both $\mathrm{G}_{\mathrm{i}}$-coupled receptors. Similarly to JNJ39758979, losartan has also been reported to reduce NHE3 expression (102). However, the possibility of it being an indirect effect exerted by JNJ39758979 and secondary to RAAS modulation could not be ruled out. Moreover, even if JNJ39758979 is a selective $\mathrm{H}_{4} \mathrm{R}$ antagonist, a class-effect has to be demonstrated to affirm whether $\mathrm{H}_{4} \mathrm{R}$-dependent downstream signals are responsible for the detrimental effect of 
histamine on the tubular reabsortive machinery. If we consider the other reabsorption pathways in the tubules, the correlation with histamine becomes even more speculative. An explicative example can be found in the potential contribution of histamine to water-balance in the kidneys, which is usually dysregulated in DN, leading to the onset of polyuria. Several water channels, named aquaporins (AQPs), are involved in water transport across the epithelia. At least 9 types, including AQP-1-8 and AQP-11 that are present at distinct sites and have specific functions, have been identified in the kidneys (103). In particular, AQP-2 and AQP-5 urinary excretion has been observed to increase significantly in DN patients and a positive correlation between AQP level in urine and the histological class of DN has been established. Indeed, AQP-2 and AQP-5 were appointed as novel non-invasive biomarkers to help in classifying the clinical stage of DN (103). Interestingly, an in vitro study on human nasal epithelial cells has revealed that histamine down-regulates AQP5 expression via NF- $\kappa$ B activation and the consequent reduction in the phosphorylation of cyclic adenosine monophosphate (cAMP) response element-binding protein $(\mathrm{CREB})(104,105)$. These effects were mediated by $\mathrm{H}_{1} \mathrm{R}$, as demonstrated by the ability of chlorpheniramine to reverse histamine's inhibitory effect (105). Moreover, $\mathrm{H}_{1} \mathrm{R}$ activation induced AQP-5 translocation to the plasma membrane in human submandibular gland cells, which, at least partly, explains the xerostomia that is induced by the classic antihistaminic anti- $\mathrm{H}_{1} \mathrm{R}$ drugs (106). Histamine has also been found to induce gastric AQP-4 rearrangement and down-regulation (107). It is therefore possible that histamine may also modulate AQP expression, via $\mathrm{H}_{1} \mathrm{R}$ and/or other HRs, in other epithelial cells, such as renal epithelial cells, according to their differential distribution. A deeper investigation of this issue would contribute to better understanding the mechanism that underlies the anti-polyuric effect that is exerted by both levocetirizine (56), and JNJ39758979 (19).

\section{Conclusion}

Spare evidence has been provided as to histamine's possible role in DN in past decades (108). Although its vasoactive and inflammatory properties may make histamine's role in DN progression plausible, this idea has not been thoroughly investigated. Initial data did not clearly establish its direct 
contribution to renal pathophysiology, meaning that this amine has been relegated to the background of diabetic disease, and its role in DN development has not been recognised. Only two studies have investigated the effect of an antihistaminergic approach on DN, both in recent years. These studies suggest that histamine is involved in renal injury and both the selective histamine antagonism, at $\mathrm{H}_{1} \mathrm{R}$ by levocetirizine (56), and at $\mathrm{H}_{4} \mathrm{R}$ by JNJ39758979 (19), were able to prevent/reduce renal damage. However, defining whether these beneficial effects are due to the selective contribution of the HRs in the kidney is still quite the challenge. While improved glycaemic status in diabetic rats was reported with levocetirizine (56), the same positive effect was not observed with JNJ39758979 (19). It can therefore be stated that at least $\mathrm{H}_{4} \mathrm{R}$ seems to have a selective role in renal function. However, $\mathrm{H}_{1} \mathrm{R}$ has been demonstrated to also have specific effects on podocyte junctional integrity, at least in vitro, which may contribute to renal protection. Nevertheless, the fact that indirect effects are induced by limiting the anti-inflammatory response can be recognised for both $\mathrm{H}_{1} \mathrm{R}$ and $\mathrm{H}_{4} \mathrm{R}$ antagonism. This evidence supports the idea that histamine, due to its pleiotropic actions, may simultaneously and differentially act on all the components of the vicious circle; glomerular hyper-filtration, tubular inflammation, tubular hypertrophy and fibrosis establishment. Indeed, as described in Figure $1, \mathrm{H}_{1} \mathrm{R}$ antagonism potentially maintains glomerular integrity $(17,56)$, while $\mathrm{H}_{4} \mathrm{R}$ antagonism protects against reabsorptive dysfunction, counteracting the unbalance of megalin/NHE3 expression at the proximal tubule (19). Both strategies are simultaneously effective in preventing the pro-inflammatory and pro-fibrotic cascade, which leads to the loss of kidney function $(19,56)$. The roles of $\mathrm{H}_{2} \mathrm{R}$ and $\mathrm{H}_{3} \mathrm{R}$ are still far from being clear. However, their localisation along the nephron means that they may subserve water homeostasis, while $\mathrm{H}_{2} \mathrm{R}$ probably contributes to glomerular mechanical damage.

Targeting histamine might therefore be a novel strategy for the treatment of DN with an integrated approach of vasculoprotection, chronic inflammation reduction and fibrosis prevention. However, these suggestions merit better elucidation, including first clinical evaluations, before final conclusions can be reached.

\section{Acknowledgements}


None

\section{Declarations of interest}

None to declare

\section{Funding information}

This work was funded by the University of Turin (ex60\% 2017) and University of Florence (ex60\% 2017)

\section{Author contribution statement}

ACR and AP conceived and designed the study; ACR, AP, RV drafted the article; ACR and CG critically revised the article for important intellectual content; RV and MG performed literature searches

\section{References}

1. Persson F, Rossing P. Diagnosis of diabetic kidney disease: state of the art and future perspective. Kidney International Supplements. 2018;8:2-7.

2. Maric C. Vasoactive hormones and the diabetic kidney. TheScientificWorldJournal. $2008 ; 8: 470-85$.

3. Markle RA, Hollis TM, Cosgarea AJ. Renal histamine increases in the streptozotocin-diabetic rat. Experimental and molecular pathology. 1986;44(1):21-8.

4. Gill DS, Barradas MA, Fonseca VA, Dandona P. Plasma histamine concentrations are elevated in patients with diabetes mellitus and peripheral vascular disease. Metabolism: clinical and experimental. 1989;38(3):243-7.

5. Watanabe T, Ohtsu H. L-histidine decarboxylase as a probe in studies on histamine. Chemical record. 2002;2(6):369-76. 
6. Alkan M, Machavoine F, Rignault R, Dam J, Dy M, Thieblemont N. Histidine Decarboxylase Deficiency Prevents Autoimmune Diabetes in NOD Mice. Journal of diabetes research. 2015;2015:965056.

7. Sedor JR, Abboud HE. Actions and metabolism of histamine in glomeruli and tubules of the human kidney. Kidney international. 1984;26(2):144-52.

8. Gill DS, Thompson CS, Dandona P. Histamine synthesis and catabolism in various tissues in diabetic rats. Metabolism: clinical and experimental. 1990;39(8):815-8.

9. Gill DS, Thompson CS, Dandona P. Increased histamine in plasma and tissues in diabetic rats. Diabetes research. 1988;7(1):31-4.

10. Li Y, Liu FY, Peng YM, Li J, Chen J. Mast cell, a promising therapeutic target in tubulointerstitial fibrosis. Medical hypotheses. 2007;69(1):99-103.

11. Ruger BM, Hasan Q, Greenhill NS, Davis PF, Dunbar PR, Neale TJ. Mast cells and type VIII collagen in human diabetic nephropathy. Diabetologia. 1996;39(10):1215-22.

12. Zheng JM, Yao GH, Cheng Z, Wang R, Liu ZH. Pathogenic role of mast cells in the development of diabetic nephropathy: a study of patients at different stages of the disease. Diabetologia. 2012;55(3):801-11.

13. Huang ZG, Jin Q, Fan M, Cong XL, Han SF, Gao H, et al. Myocardial remodeling in diabetic cardiomyopathy associated with cardiac mast cell activation. PloS one. 2013;8(3):e60827.

14. Holdsworth SR, Summers SA. Role of mast cells in progressive renal diseases. Journal of the American Society of Nephrology : JASN. 2008;19(12):2254-61.

15. Balakumar P, Reddy J, Singh M. Do resident renal mast cells play a role in the pathogenesis of diabetic nephropathy? Molecular and cellular biochemistry. 2009;330(1-2):187-92.

16. Schwertschlag U, Hackenthal E. Histamine stimulates renin release from the isolated perfused rat kidney. Naunyn-Schmiedeberg's archives of pharmacology. 1982;319(3):239-42. 
17. Veglia E, Pini A, Moggio A, Grange C, Premoselli F, Miglio G, et al. Histamine type 1receptor activation by low dose of histamine undermines human glomerular slit diaphragm integrity. Pharmacological research. 2016;114:27-38.

18. Morgan TK, Montgomery K, Mason V, West RB, Wang L, van de Rijn M, et al. Upregulation of histidine decarboxylase expression in superficial cortical nephrons during pregnancy in mice and women. Kidney international. 2006;70(2):306-14.

19. Pini A, Grange C, Veglia E, Argenziano M, Cavalli R, Guasti D, et al. Histamine H4 receptor antagonism prevents the progression of diabetic nephropathy in male DBA2/J mice. Pharmacological research. 2018;128:18-28.

20. Watanabe M, Suliman ME, Qureshi AR, Garcia-Lopez E, Barany P, Heimburger O, et al. Consequences of low plasma histidine in chronic kidney disease patients: associations with inflammation, oxidative stress, and mortality. The American journal of clinical nutrition. 2008;87(6):1860-6.

21. Flancbaum L, Fitzpatrick JC, Brotman DN, Marcoux AM, Kasziba E, Fisher H. The presence and significance of carnosine in histamine-containing tissues of several mammalian species. Agents and actions. 1990;31(3-4):190-6.

22. Riedl E, Pfister F, Braunagel M, Brinkkotter P, Sternik P, Deinzer M, et al. Carnosine prevents apoptosis of glomerular cells and podocyte loss in STZ diabetic rats. Cellular physiology and biochemistry : international journal of experimental cellular physiology, biochemistry, and pharmacology. 2011;28(2):279-88.

23. Hipkiss AR. Glycation, ageing and carnosine: are carnivorous diets beneficial? Mechanisms of ageing and development. 2005;126(10):1034-9.

24. Torres VE, Northrup TE, Edwards RM, Shah SV, Dousa TP. Modulation of cyclic nucleotides in islated rat glomeruli: role of histamine, carbamylcholine, parathyroid hormone, and angiotensinII. The Journal of clinical investigation. 1978;62(6):1334-43. 
25. Rosa AC, Grange C, Pini A, Katebe MA, Benetti E, Collino M, et al. Overexpression of histamine $\mathrm{H}(4)$ receptors in the kidney of diabetic rat. Inflammation research : official journal of the European Histamine Research Society [et al]. 2013;62(4):357-65.

26. Pini A, Chazot PL, Veglia E, Moggio A, Rosa AC. H3 receptor renal expression in normal and diabetic rats. Inflammation research : official journal of the European Histamine Research Society [et al]. 2015;64(5):271-3.

27. Veglia E, Grange C, Pini A, Moggio A, Lanzi C, Camussi G, et al. Histamine receptor expression in human renal tubules: a comparative pharmacological evaluation. Inflammation research : official journal of the European Histamine Research Society [et al]. 2015;64(3-4):261-70.

28. Pecis M, Azevedo MJ, Gross JL. Glomerular hyperfiltration is associated with blood pressure abnormalities in normotensive normoalbuminuric IDDM patients. Diabetes care. 1997;20(8):132933.

29. Cherney DZ, Miller JA, Scholey JW, Nasrallah R, Hebert RL, Dekker MG, et al. Renal hyperfiltration is a determinant of endothelial function responses to cyclooxygenase 2 inhibition in type 1 diabetes. Diabetes care. 2010;33(6):1344-6.

30. Cherney DZ, Sochett EB, Lai V, Dekker MG, Slorach C, Scholey JW, et al. Renal hyperfiltration and arterial stiffness in humans with uncomplicated type 1 diabetes. Diabetes care. 2010;33(9):2068-70.

31. Lewis T, Grant RT. Vascular reactions of the skin to injury. The Lancet. 1924;204(5267):27980.

32. Hollis TM, Kern JA, Enea NA, Cosgarea AJ. Changes in plasma histamine concentration in the streptozotocin-diabetic rat. Experimental and molecular pathology. 1985;43(1):90-6.

33. Orlidge A, Hollis TM. Aortic endothelial and smooth muscle histamine metabolism in experimental diabetes. Arteriosclerosis. 1982;2(2):142-50. 
34. Hollis TM, Strickberger SA. Inhibition of aortic histamine synthesis by alphahydrazinohistidine inhibits increased aortic albumin accumulation in experimental diabetes in the rat. Diabetologia. 1985;28(5):282-5.

35. Zdravkovic V, Pantovic S, Rosic G, Tomic-Lucic A, Zdravkovic N, Colic M, et al. Histamine blood concentration in ischemic heart disease patients. Journal of biomedicine \& biotechnology. 2011;2011:315709.

36. Mukai N, Hori S, Pomeroy M. Cerebral lesions in rats with streptozotocin-induced diabetes. Acta neuropathologica. 1980;51(1):79-84.

37. Stauber WT, Ong SH, McCuskey RS. Selective extravascular escape of albumin into the cerebral cortex of the diabetic rat. Diabetes. 1981;30(6):500-3.

38. McCuskey PA, McCuskey RS. In vivo and electron microscopic study of the development of cerebral diabetic microangiography. Microcirculation, endothelium, and lymphatics. 1984;1(2):22144.

39. Lorenzi M, Healy DP, Hawkins R, Printz JM, Printz MP. Studies on the permeability of the blood-brain barrier in experimental diabetes. Diabetologia. 1986;29(1):58-62.

40. Yousif K, Bebbington J, Foley B. Impact on patients triage distribution utilizing the Australasian Triage Scale compared with its predecessor the National Triage Scale. Emergency medicine Australasia : EMA. 2005;17(5-6):429-33.

41. Carmines PK. The renal vascular response to diabetes. Current opinion in nephrology and hypertension. 2010;19(1):85-90.

42. Wigg SJ, Tare M, Tonta MA, O'Brien RC, Meredith IT, Parkington HC. Comparison of effects of diabetes mellitus on an EDHF-dependent and an EDHF-independent artery. American journal of physiology Heart and circulatory physiology. 2001;281(1):H232-40.

43. Burnham MP, Johnson IT, Weston AH. Reduced Ca2+-dependent activation of largeconductance $\mathrm{Ca} 2+$-activated $\mathrm{K}+$ channels from arteries of Type 2 diabetic Zucker diabetic fatty rats. American journal of physiology Heart and circulatory physiology. 2006;290(4):H1520-7. 
44. Leo CH, Hart JL, Woodman OL. 3',4'-Dihydroxyflavonol reduces superoxide and improves nitric oxide function in diabetic rat mesenteric arteries. PloS one. 2011;6(6):e20813.

45. Zhao LM, Wang Y, Yang Y, Guo R, Wang NP, Deng XL. Metformin Restores IntermediateConductance Calcium-Activated $\mathrm{K}(+)$ Channel- and Small-Conductance Calcium-Activated $\mathrm{K}(+)$ Channel-Mediated Vasodilatation Impaired by Advanced Glycation End Products in Rat Mesenteric Artery. [Corrected]. Molecular pharmacology. 2014;86(5):580-91.

46. Killackey JJ, Johnston MG, Movat HZ. Increased permeability of microcarrier-cultured endothelial monolayers in response to histamine and thrombin. A model for the in vitro study of increased vasopermeability. The American journal of pathology. 1986;122(1):50-61.

47. Rotrosen D, Gallin JI. Histamine type I receptor occupancy increases endothelial cytosolic calcium, reduces F-actin, and promotes albumin diffusion across cultured endothelial monolayers. The Journal of cell biology. 1986;103(6 Pt 1):2379-87.

48. Hamilton KK, Sims PJ. Changes in cytosolic Ca2+ associated with von Willebrand factor release in human endothelial cells exposed to histamine. Study of microcarrier cell monolayers using the fluorescent probe indo-1. The Journal of clinical investigation. 1987;79(2):600-8.

49. Brock TA, Capasso EA. Thrombin and histamine activate phospholipase $\mathrm{C}$ in human endothelial cells via a phorbol ester-sensitive pathway. Journal of cellular physiology. 1988;136(1):54-62.

50. Carson MR, Shasby SS, Shasby DM. Histamine and inositol phosphate accumulation in endothelium: cAMP and a G protein. The American journal of physiology. 1989;257(4 Pt 1):L25964.

51. Niimi N, Noso N, Yamamoto S. The effect of histamine on cultured endothelial cells. A study of the mechanism of increased vascular permeability. European journal of pharmacology. $1992 ; 221(2-3): 325-31$. 
52. Gardner TW, Lesher T, Khin S, Vu C, Barber AJ, Brennan WA, Jr. Histamine reduces ZO-1 tight-junction protein expression in cultured retinal microvascular endothelial cells. The Biochemical journal. 1996;320 ( Pt 3):717-21.

53. Gardner TW. Histamine, ZO-1 and increased blood-retinal barrier permeability in diabetic retinopathy. Transactions of the American Ophthalmological Society. 1995;93:583-621.

54. Gardner TW, Lieth E, Antonetti A, Berber AJ. A new hypothesis on mechanism of retinal vascular permeability in diabetes. In: Friedman EA, L'Esperance FAJ, editors. Diabetic Renal-Retinal Syndrome: Springer Netherlands; 1998. p. 169-79.

55. Gardner TW, Sander B, Larsen ML, Kunselman A, Tenhave T, Lund-Andersen H, et al. An extension of the Early Treatment Diabetic Retinopathy Study (ETDRS) system for grading of diabetic macular edema in the Astemizole Retinopathy Trial. Current eye research. 2006;31(6):535-47.

56. Anbar HS, Shehatou GS, Suddek GM, Gameil NM. Comparison of the effects of levocetirizine and losartan on diabetic nephropathy and vascular dysfunction in streptozotocininduced diabetic rats. European journal of pharmacology. 2016;780:82-92.

57. Zampeli E, Tiligada E. The role of histamine H4 receptor in immune and inflammatory disorders. British journal of pharmacology. 2009;157(1):24-33.

58. Bakker RA, Schoonus SB, Smit MJ, Timmerman H, Leurs R. Histamine H(1)-receptor activation of nuclear factor-kappa B: roles for $G$ beta gamma- and $G$ alpha(q/11)-subunits in constitutive and agonist-mediated signaling. Molecular pharmacology. 2001;60(5):1133-42.

59. Grosicki M, Wojcik T, Chlopicki S, Kiec-Kononowicz K. In vitro study of histamine and histamine receptor ligands influence on the adhesion of purified human eosinophils to endothelium. European journal of pharmacology. 2016;777:49-59.

60. Ling P, Ngo K, Nguyen S, Thurmond RL, Edwards JP, Karlsson L, et al. Histamine H4 receptor mediates eosinophil chemotaxis with cell shape change and adhesion molecule upregulation. British journal of pharmacology. 2004;142(1):161-71. 
61. Godot V, Arock M, Garcia G, Capel F, Flys C, Dy M, et al. H4 histamine receptor mediates optimal migration of mast cell precursors to CXCL12. The Journal of allergy and clinical immunology. 2007;120(4):827-34.

62. Dai DF, Sasaki K, Lin MY, Smith KD, Nicosia RF, Alpers CE, et al. Interstitial eosinophilic aggregates in diabetic nephropathy: allergy or not? Nephrology, dialysis, transplantation : official publication of the European Dialysis and Transplant Association - European Renal Association. 2015;30(8):1370-6.

63. Busse WW, Sosman J. Histamine inhibition of neutrophil lysosomal enzyme release: an H2 histamine receptor response. Science. 1976;194(4266):737-8.

64. Ferstl R, Akdis CA, O'Mahony L. Histamine regulation of innate and adaptive immunity. Frontiers in bioscience. 2012;17:40-53.

65. Li H, Guo D, Zhang L, Feng X. Glycyrrhizin attenuates histamine-mediated MUC5AC upregulation, inflammatory cytokine production, and aquaporin 5 downregulation through suppressing the NF-kappaB pathway in human nasal epithelial cells. Chemico-biological interactions. 2018;285:21-6.

66. Charlesworth EN, Kagey-Sobotka A, Norman PS, Lichtenstein LM. Effect of cetirizine on mast cell-mediator release and cellular traffic during the cutaneous late-phase reaction. The Journal of allergy and clinical immunology. 1989;83(5):905-12.

67. Jinquan T, Reimert CM, Deleuran B, Zachariae C, Simonsen C, Thestrup-Pedersen K. Cetirizine inhibits the in vitro and ex vivo chemotactic response of $\mathrm{T}$ lymphocytes and monocytes. The Journal of allergy and clinical immunology. 1995;95(5 Pt 1):979-86.

68. Arnold R, Rihoux J, Konig W. Cetirizine counter-regulates interleukin-8 release from human epithelial cells (A549). Clinical and experimental allergy : journal of the British Society for Allergy and Clinical Immunology. 1999;29(12):1681-91.

69. Shimizu T, Nishihira J, Watanabe H, Abe R, Ishibashi T, Shimizu H. Cetirizine, an H1receptor antagonist, suppresses the expression of macrophage migration inhibitory factor: its potential 
anti-inflammatory action. Clinical and experimental allergy : journal of the British Society for Allergy and Clinical Immunology. 2004;34(1):103-9.

70. Shankar A, Sun L, Klein BE, Lee KE, Muntner P, Nieto FJ, et al. Markers of inflammation predict the long-term risk of developing chronic kidney disease: a population-based cohort study. Kidney international. 2011;80(11):1231-8.

71. Pruijm M, Ponte B, Vollenweider P, Mooser V, Paccaud F, Waeber G, et al. Not all inflammatory markers are linked to kidney function: results from a population-based study. American journal of nephrology. 2012;35(3):288-94.

72. Duran-Salgado MB, Rubio-Guerra AF. Diabetic nephropathy and inflammation. World journal of diabetes. 2014;5(3):393-8.

73. Kohka H, Nishibori M, Iwagaki H, Nakaya N, Yoshino T, Kobashi K, et al. Histamine is a potent inducer of IL-18 and IFN-gamma in human peripheral blood mononuclear cells. Journal of immunology. 2000;164(12):6640-6.

74. Takahashi HK, Yoshida A, Iwagaki H, Yoshino T, Itoh H, Morichika T, et al. Histamine regulation of interleukin-18-initiating cytokine cascade is associated with down-regulation of intercellular adhesion molecule-1 expression in human peripheral blood mononuclear cells. The Journal of pharmacology and experimental therapeutics. 2002;300(1):227-35.

75. Ramseyer VD, Garvin JL. Tumor necrosis factor-alpha: regulation of renal function and blood pressure. American journal of physiology Renal physiology. 2013;304(10):F1231-42.

76. Im SJ, Ahn MH, Han IH, Song HO, Kim YS, Kim HM, et al. Histamine and TNF-alpha release by rat peritoneal mast cells stimulated with Trichomonas vaginalis. Parasite. 2011;18(1):4955.

77. Maurer M, Opitz M, Henz BM, Paus R. The mast cell products histamine and serotonin stimulate and TNF-alpha inhibits the proliferation of murine epidermal keratinocytes in situ. Journal of dermatological science. 1997;16(1):79-84. 
78. Wang J, Al-Lamki RS, Zhang H, Kirkiles-Smith N, Gaeta ML, Thiru S, et al. Histamine antagonizes tumor necrosis factor (TNF) signaling by stimulating TNF receptor shedding from the cell surface and Golgi storage pool. The Journal of biological chemistry. 2003;278(24):21751-60.

79. Vannier E, Miller LC, Dinarello CA. Histamine suppresses gene expression and synthesis of tumor necrosis factor alpha via histamine $\mathrm{H} 2$ receptors. The Journal of experimental medicine. 1991;174(1):281-4.

80. Steffel J, Akhmedov A, Greutert H, Luscher TF, Tanner FC. Histamine induces tissue factor expression: implications for acute coronary syndromes. Circulation. 2005;112(3):341-9.

81. Steffel J, Arnet C, Akhmedov A, Iseli SM, Luscher TF, Tanner FC. Histamine differentially interacts with tumor necrosis factor-alpha and thrombin in endothelial tissue factor induction: the role of c-Jun NH2-terminal kinase. Journal of thrombosis and haemostasis : JTH. 2006;4(11):2452-60.

82. Lee SB, Kalluri R. Mechanistic connection between inflammation and fibrosis. Kidney international Supplement. 2010(119):S22-6.

83. Ferenbach D, Kluth DC, Hughes J. Inflammatory cells in renal injury and repair. Seminars in nephrology. 2007;27(3):250-9.

84. Lopez-Perra V, Mallavia B, Egido J, Gomez-Guerrero C. Immunoinflammation in Diabetic Nephropathy: Molecular Mechanisms and Therapeutic Options. In: Chan J, editor. Diabetic Nephropathy: InTech; 2012. p. 127-46.

85. Triggiani M, Petraroli A, Loffredo S, Frattini A, Granata F, Morabito P, et al. Differentiation of monocytes into macrophages induces the upregulation of histamine H1 receptor. The Journal of allergy and clinical immunology. 2007;119(2):472-81.

86. Czerner CP, Klos A, Seifert R, Neumann D. Histamine induces chemotaxis and phagocytosis in murine bone marrow-derived macrophages and RAW 264.7 macrophage-like cells via histamine H4-receptor. Inflammation research : official journal of the European Histamine Research Society [et al]. 2014;63(3):239-47. 
87. Zwadlo-Klarwasser G, Braam U, Muhl-Zurbes P, Schmutzler W. Macrophages and lymphocytes: alternative sources of histamine. Agents and actions. 1994;41 Spec No:C99-100.

88. El Mesallamy HO, Ahmed HH, Bassyouni AA, Ahmed AS. Clinical significance of inflammatory and fibrogenic cytokines in diabetic nephropathy. Clinical biochemistry. 2012;45(9):646-50.

89. Fan JM, Ng YY, Hill PA, Nikolic-Paterson DJ, Mu W, Atkins RC, et al. Transforming growth factor-beta regulates tubular epithelial-myofibroblast transdifferentiation in vitro. Kidney international. 1999;56(4):1455-67.

90. Oldfield MD, Bach LA, Forbes JM, Nikolic-Paterson D, McRobert A, Thallas V, et al. Advanced glycation end products cause epithelial-myofibroblast transdifferentiation via the receptor for advanced glycation end products (RAGE). The Journal of clinical investigation. 2001;108(12):1853-63.

91. Gewin L, Zent R. How does TGF-beta mediate tubulointerstitial fibrosis? Seminars in nephrology. 2012;32(3):228-35.

92. Chakraborty S, Chopra P, Ambi SV, Dastidar SG, Ray A. Emerging therapeutic interventions for idiopathic pulmonary fibrosis. Expert opinion on investigational drugs. 2014;23(7):893-910.

93. Trachtman H, Fervenza FC, Gipson DS, Heering P, Jayne DR, Peters H, et al. A phase 1, single-dose study of fresolimumab, an anti-TGF-beta antibody, in treatment-resistant primary focal segmental glomerulosclerosis. Kidney international. 2011;79(11):1236-43.

94. Rosa AC, Pini A, Lucarini L, Lanzi C, Veglia E, Thurmond RL, et al. Prevention of bleomycin-induced lung inflammation and fibrosis in mice by naproxen and JNJ7777120 treatment. The Journal of pharmacology and experimental therapeutics. 2014;351(2):308-16.

95. Lucarini L, Pini A, Rosa AC, Lanzi C, Durante M, Chazot PL, et al. Role of histamine H4 receptor ligands in bleomycin-induced pulmonary fibrosis. Pharmacological research. 2016;111:7408. 
96. Meng XM, Huang XR, Chung AC, Qin W, Shao X, Igarashi P, et al. Smad2 protects against TGF-beta/Smad3-mediated renal fibrosis. Journal of the American Society of Nephrology : JASN. 2010;21(9):1477-87.

97. Lan HY. Diverse roles of TGF-beta/Smads in renal fibrosis and inflammation. International journal of biological sciences. 2011;7(7):1056-67.

98. Lan HY, Chung AC. TGF-beta/Smad signaling in kidney disease. Seminars in nephrology. 2012;32(3):236-43.

99. Meng XM, Chung AC, Lan HY. Role of the TGF-beta/BMP-7/Smad pathways in renal diseases. Clinical science. 2013;124(4):243-54.

100. Girardi AC, Di Sole F. Deciphering the mechanisms of the $\mathrm{Na}+\mathrm{H}+$ exchanger-3 regulation in organ dysfunction. American journal of physiology Cell physiology. 2012;302(11):C1569-87.

101. Zerbini G, Gabellini D, Maestroni S, Maestroni A. Early renal dysfunctions in type 1 diabetes and pathogenesis of diabetic nephropathy. Journal of nephrology. 2007;20 Suppl 12:S19-22.

102. Queiroz-Leite GD, Peruzzetto MC, Neri EA, Reboucas NA. Transcriptional regulation of the $\mathrm{Na}(+) / \mathrm{H}(+)$ exchanger NHE3 by chronic exposure to angiotensin II in renal epithelial cells. Biochemical and biophysical research communications. 2011;409(3):470-6.

103. Rossi L, Nicoletti MC, Carmosino M, Mastrofrancesco L, Di Franco A, Indrio F, et al. Urinary Excretion of Kidney Aquaporins as Possible Diagnostic Biomarker of Diabetic Nephropathy. Journal of diabetes research. 2017;2017:4360357.

104. Wang W, Wang X, Ma L, Zhang R. Histamine downregulates aquaporin 5 in human nasal epithelial cells. American journal of rhinology \& allergy. 2015;29(3):188-92.

105. Chang YL, Lin CS, Wang HW, Jian KR, Liu SC. Chlorpheniramine attenuates histaminemediated aquaporin 5 downregulation in human nasal epithelial cells via suppression of NF-kappaB activation. International journal of medical sciences. 2017;14(12):1268-75. 
106. Kim JH, Park SH, Moon YW, Hwang S, Kim D, Jo SH, et al. Histamine H1 receptor induces cytosolic calcium increase and aquaporin translocation in human salivary gland cells. The Journal of pharmacology and experimental therapeutics. 2009;330(2):403-12.

107. Carmosino M, Procino G, Nicchia GP, Mannucci R, Verbavatz JM, Gobin R, et al. Histamine treatment induces rearrangements of orthogonal arrays of particles (OAPs) in human AQP4expressing gastric cells. The Journal of cell biology. 2001;154(6):1235-43.

108. Pini A, Obara I, Battell E, Chazot PL, Rosa AC. Histamine in diabetes: Is it time to reconsider? Pharmacological research. 2016;111:316-24.

\section{Figure caption}

Figure 1. Histamine's role in the development and progression DN.

\section{Figure 2. Histamine receptors in the pathophysiology of DN.}

$\mathrm{DN}$ is accompanied by an increase in renal histamine content, which can trigger and/or sustain the vicious circle established by glomerular mechanical damage, tubular inflammation, fibrosis development and tubular reabsorptive dysfunction. The strongest evidence has been found for $\mathrm{H}_{4} \mathrm{R}$, which is localised on the proximal tubule (a) and on the loop of Henle (d), and is involved in tubular inflammation, fibrosis and reabsorptive dysfunction. Besides promoting tubular inflammation, $\mathrm{H}_{1} \mathrm{R}$ may be involved in glomerular injury, which is consistent with its localisation in the glomerulus, but also in the tubule in both the proximal (a) and distal (b) tract. A similar effect for $\mathrm{H}_{2} \mathrm{R}$, which is again present in the glomerulus and distal tubule (b), can be just hypothesised. A possible role for $\mathrm{H}_{3} \mathrm{R}$ in reabsorptive dysfunction can be hypothesised on the basis of its localisation in the collecting duct (c). 